\title{
Taşlama Makinalarında PLC Kullanılarak Otomatik Taşlama Uygulaması
}

\author{
Ayşe Kocalmış Bilhan ${ }^{1 *}$, Mahmut Cemal Kabak ${ }^{2}$

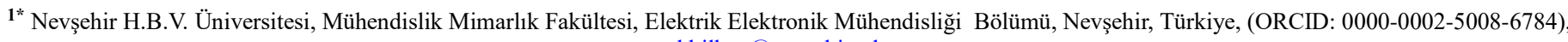 \\ akbilhan@nevsehir.edu.tr \\ ${ }^{2}$ Nevşehir H.B.V. Üniversitesi, Elektrik Elektronik Mühendisliği Ana Bilim Dalı Yüksek Lisans Öğrencisi, Nevşehir, Türkiye (ORCID: 0000-0003-4572-9463), \\ mckabak@hotmail.com
}

(2nd International Conference on Access to Recent Advances in Engineering and Digitalization (ARACONF)-10-12 March 2021)

(DOI: 10.31590/ejosat.900022)

ATIF/REFERENCE: Kocalmış Bilhan, A. \& Kabak M.C. (2021). Taşlama Makinalarında PLC Kullanılarak Otomatik Taşlama Uygulamas1. Avrupa Bilim ve Teknoloji Dergisi, (24), 252-257.

\section{$\ddot{O} \mathbf{z}$}

Sanayi devrimiyle birlikte üretim teknolojileri ve ürünleri hızlı bir gelişme süreci içerisine girdi. Günümüzde üretim sistemleri, makineler, operatörler, ürünler vb gibi birçok alanda mikroişlemci tabanlı kontrolörler yaygın olarak kullanılmaktadır. Bu makineler bu kontrolörler kullanılarak hem bir bilgisayar yardımıyla gözlenebilmekte hem de sonuçlar bir rapor halinde sunulabilmektedir. Bunun yanı sıra çeştli iletişim teknolojileri kullanılarak, sistemlerin birbirleri ile haberleşmeleri sağlanmasıyla uzaktan kontrol gibi yöntemlerin ortaya çıkmasına sebep olmuştur. Bu çalışmada da gerçekleştirilen Programlanabilir Lojik Kontorolör (PLC) kullanılarak tasarlanan sanayi tipi taşlama tezgahının otomasyonu ve çalışması anlatılmaktadır.

\section{An Applicaiton of Automatic Stone Grinding in Grinding Machines By Using PLC}

\begin{abstract}
With the industrial revolution, industrial technologies and products have increased rapidly. Today, microprocessor-based controllers are widely used in many areas such as production systems, machines, operators, products, etc. By using these controllers, machines or processes can be observed with the help of a computer and the results can be presented in a report. In addition, by using various communication technologies, the systems can communicate with each other, leading to the emergence of methods such as remote control. In this study, the automation and operation of an industrial type grinding machine designed using a Programmable Logic Controller (PLC) is explained.
\end{abstract}

Keywords: Grinding Machines, PLC, Controller, Programmer..

\footnotetext{
*Sorumlu Yazar: akbilhan@,nevsehir.edu.tr
} 


\section{Giriş}

18. yy sonunda su ve buhar enerjisi kullanılarak çalışan makinelerin üretilmesiyle başlayan birinci sanayi devrimi günümüzde artık siber- fiziksel sistemlere ve dinamik veri işlemeye dayalı üretim sistemlerinin ortaya çıkmasıyla dördüncü sanayi devrimi adını alarak literatürde yerini almaktadır [1-3]. Özellikle 60'lı yılların sonu ile 70'li yılların başlarında başlayan elektronik eleman ve devrelerin gün geçtikçe gelişmesi ve hemen hemen her alanda yaygın olarak kullanılmaya başlanmasıyla mikroişlemci tabanlı birçok programlayıcı geliştirilmiştir. Özellikle 1969 yılında PLC (Programlanabilir Lojik Kontrolörler) adı verilen kontorlörlerin tasarlanmasıyla 3. Endüstri devriminin temelleri atılmış ve bilgisayların ve bunlarla beraber otomasyon sistemlerinin gelişmesine ön ayak olmuştur. [1]. Günümüzde özellikle otomotiv sanayi, sağlık sektörü, üretim teknoloji v.b. hassas uygulamanın gerektiği alanlarda yeni teknolojiler geliştirilmiş ve kullanılmaya başlanmıştır. Bu gelişmiş teknolojik ürünler hem nüfusun hızla artmasıyla doğan ihtiyaçaların üretimini kolaylaştırmış hemde üretim sürecinin daha hızlı olmasını sağlamıştır [2,3,4].

Zaman içerisinde gerek malzeme bilgisinin gelişmesi gerek ise elektrik/elektronik alanda meydana gelen gelişmeler, hassas servo motorların üretilmesi gerektiğini ortaya koydu. Bu hassas motorlar tek başlarına kullanılamayacaklarından ötürü beraber kullanılan malzemelerin de (vidalı millerin, kızakların veya motor flanşlarının) benzer hassasiyetlere sahip olması gerekir. $\mathrm{Bu}$ nedenle, bu malzemeleri üretmek için birçok makine geliştirilmiştir. Özellikle sanayide döküm işlemi yapabilmek için için dişi-dişi veya erkek-dişi kalıplara ihtiyaç duyulur. Bu kalıplar karşı karşıya birleştirildiği zaman dökülen metalin birleşme noktalarından sızmaması için iyi işlenmiş olması gerekmektedir. $\mathrm{Bu}$ hassasiyeti gerçekleştirebilmek için ise taşlama makineleri kullanılmaktadır. Taşlama makineleri endüstride, üniversal, nümerik kontrollü (NC) veya bilgisayarlı nümerik kontrol (CNC) olarak kullanılmaktadır. Üniversal makineler düşük maliyetli olduğundan dolayı ilk zamanlardan itibaren yaygın olarak tercih edilmektedir. Ancak maliyeti yüksek olsada CNC taşlama makineleri hassasiyetin yüksek olduğu ve üretimin yoğun olduğu yerlerde kullanılırlar. NC makineler ise fiyatları üniversal tezgâhlara göre yüksek olsa da üniversal tezgâhların kısmen bilgisayar kullanılarak hassaslaştırılmış halidir. Gelişen teknoloji, hızlanmayı ve beraberinde hassas çalışmayı da gerektirdiğinden ve uygun maliyetlerinden dolayı NC makinelerin kullanımı oldukça yaygindir [5].

Bunun yanı sıra yapılan birçok çalışmada yakın gelecekte fosil yaktıların tükeneceği, bu yakıtların kullanımı ile ortaya çıkan atıkların büyük oranda çevre kirliliğine sebep olduğu gösterilmiştir. Ancak nüfusun hızlı olarak artması, ihtiyaçların da günden güne hızlı bir şekilde temin edilmesini gerektirmektedir. Her sektör (yiyecek üretimi, kıyafet üretimi, inşaat işleri, araç üretimi vs.) için geçerli olan hızlı tüketim, hızlı üretimin zorunlu hale gelmesine sebep olmuştur. $\mathrm{Bu}$ nedenle de günümüzde birçok üretim tesisi farklı markalara ait otomasyon sistemi kullanmaya başlamıştır. Günümüzde büyük/küçük birçok işletmede, fabrikada Programlanabilir Mantık Devreleri (PLC) adı verilen bilgisayar destekli tasarım yöntemi kullanılmaktadır. Özellikle imalat sektörünün geleneksel yöntemlerden sıyrılarak kendine yeni bir çalışma alanı bulduğu durumlarda akıllı sistemler oldukça büyük bir önem kazanmıştır [6].
$\mathrm{Bu}$ çalışmada, taşlama tezgâhlarında taşlamada son derece önemli olan taş bileme işleminin PLC programlayıcı kullanılarak, tamamen maliyetsiz, hızlı ve hassas bir şekilde otomatik olarak yapılması gösterilmektedir.

\section{Materyal ve Metot}

\subsection{Taşlama İşıemi ve Taşlama Tezgâhları}

Taşlama, belirli bir formda imal edilmiş olan sert aşındırıcı tanecikler içeren kesici (Zımpara taşı) ile iş parçası üzerinden çok noktadan (taş genişliği kadar bir yüzey söz konusudur) talaş kaldırma işlemine denir. Yüzeyden bir aşındırıcı sayesinde parça kopararak bir nevi tesfiye eden, dönerek ilerleyen bir fener miline sahip olan ve hassas işlemelerde kullanılan tezgâhlara taşlama tezgâhı adı verilir. Şekil 1'de Taşlama tezgâhları, imalatta, ölçü olarak hassasiyeti olan ve yüzeyde pürüzsüzlük oranı yüksek olan işler için kullanılır. Endüstride yaygın olarak düzlem taşlama tezgâhları, silindirik taşlama tezgâhları, puantasız taşlama tezgâhları ve $\mathrm{CNC} / \mathrm{NC}$ taşlama tezgâhları kullanılmaktadır $[7,8]$.

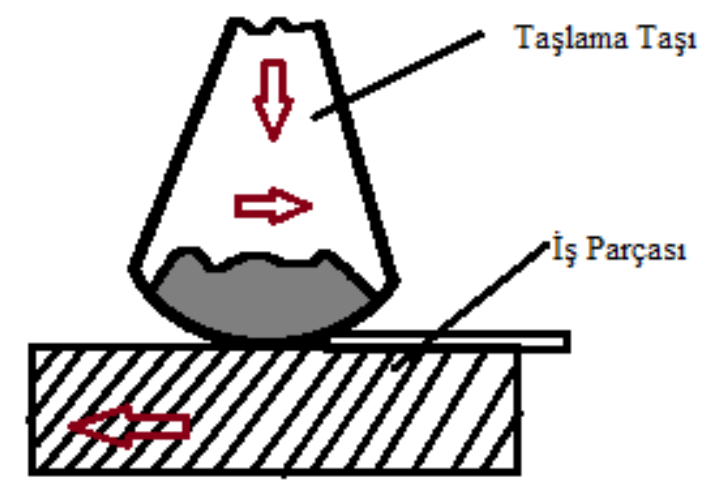

Şekill. Taşlama işlemine ait bir görsel

Düzlem taşlama tezgâhları kendi aralarında yatay ve düşey milli düzlem taşlama makinaları olmak üzere ikiye ayrılmaktadır. Silindirik taşlama makinelerinde ise silindirik iş parçalarının dış kısımlarını silindirik veya konik olarak taşlama yapılmaktadır. Puntasız taşlama makinalarında, iş parçası bağlanmadan, bir sevk kızağı üzerinde, iki taş arasından geçirilerek taşlama işlemi yapılır [9].

Nümerik kontrollü sistemler (NC) ise ilk olarak 1950'li yıllarda kullanılmaya başlanmıştır. NC, takım tezgâhlarının sayı harf vb. sembollerden ( $\mathrm{G}, \mathrm{M}$ kodları veya özel komutlar) meydana gelen ve belirli bir mantığa göre kodlanmış komutlar yardımıyla işletilmesidir. Ancak günümüzde bilgisayar teknolojisinin gelimesiyle CNC sistemler daha popüler hale gelmiştir. CNC sistemler ile bilgisayar ortamında hazırlanan bir program ile insan eli değmesinin en düşük seviyelerde olduğu, bir parçanın işlenmesi veya işin yapılması sağlanabilmektedir. Daha önceden bu işlemler insan gücüyle yapıldığından üretim esnasında hem verim kaybı hemde ürünler arasında küçük bile olsa farklılıkların olmasına sebep olabiliryordu. Fakat CNC sistemlerin kullanılmasıyla artık bu sorunlar giderilmiştir [10]. CNC taşlama tezgâhlarında kodlanan program hafızada saklanır, gerektiği zaman defalarca kullanılır. İstenildiğinde konum değiştirme, devir sayısının değiştirilmesi ve yön değiştirimesi gibi seçenekler eklenebilir. Bunun yanı sıra CNC taşlama makineleri ne kadar hassasiyetin yüksek olduğu ve üretimin yoğun olduğu yerlerde kullanılmak istense de maliyetleri oldukça yüksektir. $\mathrm{Bu}$ nedenle küçük atölyelerde tercih edilmezler. NC makineler ise tamamen bilgisayar kontrollü 
olmakları için CNC makinelere göre çok daha uygun fiyatlıdır. Gelişen teknoloji, hızlanmayı ve hassasiyeti gerektirdiği için ve uygun maliyetlerinden dolayı NC makinelerin kullanımı giderek artmaktadır.

\subsection{Programlanabilir Mantık Denetleyiciler}

Üretim teknolojilerindeki ilerleme yapılan işlemlerde de hassasiyetin artmasına sebep olmuştur. Bu nedenle makinelerin daha hassas ve verimli şekilde çalıştırılması sağlanarak endüstriye kazandırılması için otomasyon kısmının neredeyse hatasız olarak yazılması ve sisteme entegre edilmesi gerekir. Bunun dışında yapılan çalışmanın, hataları en aza indirmek, işin yapılış zamanını azaltmak ve daha hassas işleme yapmak veya kişilerden bağımsız olmak konularından en az birine de cevap vermelidir. Günümüzde Programlanabilir Mantıksal Denetleciler (PLC/Pragrammable Logic Controller) adı verilen kontrolör hem bu sorunlara bir cevap oluşturabilmekte hemde hemen hemen tüm otomasyon sistemlerinde yaygın olarak kullanılmaktadır.

PLC'ler kısaca sensör, kontak vb. algılayıcılardan aldığı bilgiyi programlayıcı tarafından kendi yazılımı kullanılarak bilgisayar ortamında yazılan bir program göre işleyen ve çıkış birimlerine bağlanan iş elemanlarına bilgi aktaran mikro işlemci tabanlı bir cihazdır [11]. İlk ticari PLC, 1968 yılında "MODICON" firması tarafından geliştirilmiştir ve daha sonra birçok farklı firma maliyeti daha düşük ancak performansı daha yüksek PLC'ler üretmiştir [12]. Bu çalışmada MITSUBISHI firamasına ait PLC kullanılmıştır.

PLC'lerin kullanım alanları ve amaçları değişiklik göstermesine rağmen yap1 bakımından benzerlik göstermektedirler. Şekil 2'de gösterildiği gibi PLC'lerin yapısında bir güç kaynağı, merkezi işlemci ünitesi (CPU), hafıza birimi, giriş ya da algılama ünitesi (algılayıcılar, sensörler, butonlar, vs.), çıkış ya da kumanda elemanları (röleler, lambalar, sirenler, motor kontrol birimleri vs.) bulunmaktadır [13].

\section{Şekil 2. PLC'lerin yapısı}

PLC enerjilendiğinde veya çalışma durumuna getirildiğinde ilk yapılan iş, giriş (input) birimine bağlanan elemanların

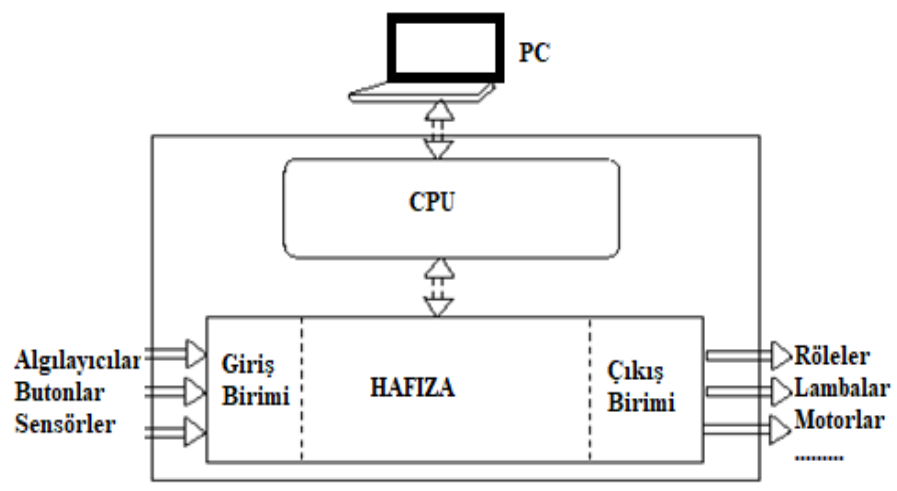

bilgileri giriş görüntü belleğine işlenir ve bu değerler bir sonraki tarama döngüsüne kadar sabit tutulur. Bunun ardından program belleğine işlenmiş komutlar sıra sıra çalıştırılır. $\mathrm{Bu}$ işlem basamakları sonucunda elde edilen çıkış bilgileri çıkış görüntü belleğine aktarılarak çıkış birimine gönderilir. Bu işlemler dizisi devamlı olarak tekrar edilir. Bu işlemlerin toplamına bir çevrim süresi adı verilir. Yazılan programların hafızadaki büyüklüğüne göre değişen döngü süreleri milisaniye seviyelerinde olup, mikro saniye seviyesinde olan PLC tipleri de mevcuttur [13].

\section{Araştırma Sonuçları ve Tartışma}

\subsection{Elektrik Projesi}

Bir makine veya sistem tasarlanırken projelendirilmesi; malzeme seçimi, PLC programının gidişatı ve tasarımı, üretim sürecinde karşılaşılabilecek sorunların belirlenmesi gibi konularda bir harita niteliği taşır. Elektrik projesi, sistemde oluşabilecek hataların giderilmesini önceden görerek planlı bir gidişatı uygulayıcıya sunar. Seri üretim yapılacaksa, üzerine koyarak ilerlemede büyük bir yardımcı ve kaynak olur.

Şekil 3 ile PLC kullanılarak tasarlanan otomatik taş bileme makinesinin kontolörüne ait güç şemasının bir bölümü verilmiştir.

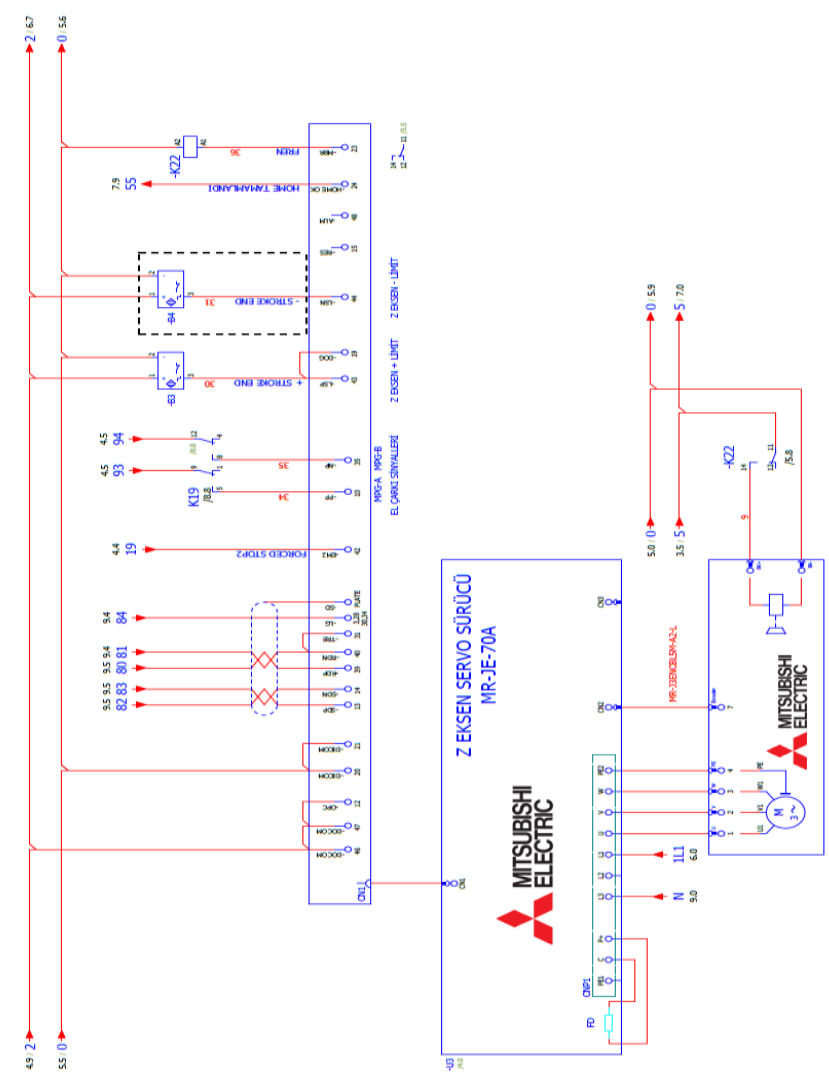

Şekil 3. Z Eksen Sürücüsü Elektrik Projesi

Makine 3 eksenli olarak tasarlanmıştır. Bunların biri, X ekseninin hareketi olan ve hidrolik olarak kontrol edilen eksendir. Taşlama makinelerinde X boyunca hareket genellikle hassasiyeti olmayan, git-gel prensibiyle ve sürekli hareket eden eksendir. Bu eksen bu nedenle hidrolik kontrollü olarak seçilir. Bu sayede yüksek güç sağlanmış, aynı zamanda hassasiyetine önem verilmeyen bir hareket ortaya çıkmış olur. Hidrolik eksen hız ayarı, üzerinde oransal valf bulunan bir üniteye $+10 \mathrm{VDC} /-$ 10VDC arası gerilim verilerek sağlanır. "+" gerilimler eksenin pozitif yönde, “_“ gerilimler ise eksenin negatif yönde ilerlemesini sağlar. Gerilimin genliği yani voltaj değeri ise eksen hareket hızını belirler. Bunu yaparken valf bobinini gerilim kadar çekerek o oranda itme kuvveti oluşmasını sağlayarak yapar.

Makinedeki diğer eksenler servo motorlarla hareketi sağlanan hassas işleme yapan eksenlerdir. Burada motorlar PLC ile haberleşirken RS232 soketi üzerinden veya PLC'den aldığ1 
bilgilerle hareketi algılar. Sürücüler üzerinden SDP, SDN, RDP ve RDN pinlerine hareket ile ilgili bilgiler gönderilir.

Sürücülere eksenlerin durması gereken yerler "HARDLIMIT" olarak adlandırılan eksen son sınırlarının bilgisi de, direkt sensör sinyalinden alınarak girilmiştir. Makine ilk açıldığında referanslar da bu sensörlerden gelen bilgiler yardımıla bilinecektir. Eksen referansa gittiğinde home tamamlandığını PLC ye bildirecek bir sinyal yine sürücüler üzerinden gönderilecektir. MR-JE-70A sürücüler üzerinde el çarkı sinyallerinin okunabileceği bir giriş de mevcuttur. Fakat el çarkı sinyalleri eksen seçimine göre olacağı için çift kontaklı bir röle yardımıyla PLC ye seçtirilmiştir. Seçilen eksen PLC ye sinyal olarak gidecek, bu bilgiye göre PLC röle seçimi yapacak el çarkından gelen A ve B sinyalleri sürücülere gönderilecektir.

Eksen sürücülerinin servo motorlarla olan iletişimleri enkoder kabloları ile sağlanmaktadır. Ayrıca sürücülerden motorlara, güç kabloları da gitmektedir. Güç kabloları haricen değil sürücü üzerinden alınmasının sebebi, verilen bilgilere göre hareket etmesini sağlamaktır.

Sürücülere eksen sınırlarını bildiren sensör sinyalleri girilmiştir. $\mathrm{Y}$ ve $\mathrm{Z}$ ekseni HARD-LIMIT sensörleri CN1 soketinin 43 ve 44 numaralı pinlerine girilmiştir. Girilen sensörün hangi yönde sınır belirleyeceği sürücü parametreleri üzerinden ayarlanabilmektedir. Girilen sinyaller aynı zamanda referans noktalarını da belirttiği için 19 numaralı pin e gelen sinyallerden referans noktasını bildiren pin'in sinyali de kisa devre edilmiştir. 19 numaralı pin "home" sinyali girişidir. PLC yazılımına göre eksen home noktasını görene kadar hareket edecek ve sensörü geçene kadar 5mm aksi yönde ilerleyecektir.

Eksen sürücüleri arasındaki diğer fark ise $\mathrm{Z}$ ekseninin aşağ1 yönde limit sensörünün bulunmamasıdır. Aşağı yönde hareket ederken $\mathrm{Z}$ ekseninin alt sınırını belirleyecek bir kıstas yoktur. Çünkü makinede manyetik tabla çıkarılarak da çalışma yapılabilmektedir. Aynı zamanda taş boyutları küçüldükçe düşey eksen daha aşağı inmesi gerekecektir. Bu durumlarda taşın çap1 gibi makine tarafından bilinmeyen ve değişen özelliklerden dolayı düşey eksene alt sınır sensörü konmamıştır.

\section{2 İş Mili Sürücüsü ve Analog Sinyaller}

Şekil 4 ile iş milini süren invertere ait elektrik projesi gösterilmektedir. İş mili eviricisi bir çeşit özelleştirilmiş frekans eviricisidir. Frekans eviricileri şebekenden aldığ frekansları içerisindeki kondansatör, bobin gibi devre elemanlarıyla artırıp azaltabilir. Bu şekilde çıkışına farklı frekanslarda gerilim vererek AC motorların çalışma hızını değiştirirler. AC motorların hızı Denklem 1 ile hesaplanır.

$n_{s}=\frac{120 . f}{P}$

Bu denklemde; Burada $\mathrm{n}_{\mathrm{s}}$ hızı, f frekansı, $\mathrm{P}$ ise kutup sayısını ifade etmektedir.. Frekans eviricisi, Mitsubishi FR A840 modeli olarak seçilmiştir. $\mathrm{Bu}$ model üzerinde Ethernet haberleşmesi mevcuttur. $\mathrm{Bu}$ sayede PLC ile haberleşebilir ve bilgi gönderebilir. Aynı zamanda bu evirici modülü üzerinde analog giriş çıkışları olan basit bir PLC de mevcuttur. Sistemde kullanılması gereken analog giriş çıkışlar, PLC üzerinde yeni bir modül gerektirdiği için eviriciden haberleşme ile alınarak PLC ye girilmiştir.

Evirici üzerinde değerlendirilen analog sinyaller sistemin çıkışlarını etkileyecek şekilde ethernet bağlantısı ile ilişkilendirilmiştir. $\mathrm{Bu}$ şekilde bağlı sistemlere MODBUS denmektedir. Modbus ile bağlı sistemlerin birbirleri ile haberleşmesi ise PROFIBUS olarak adlandırılmaktadır.

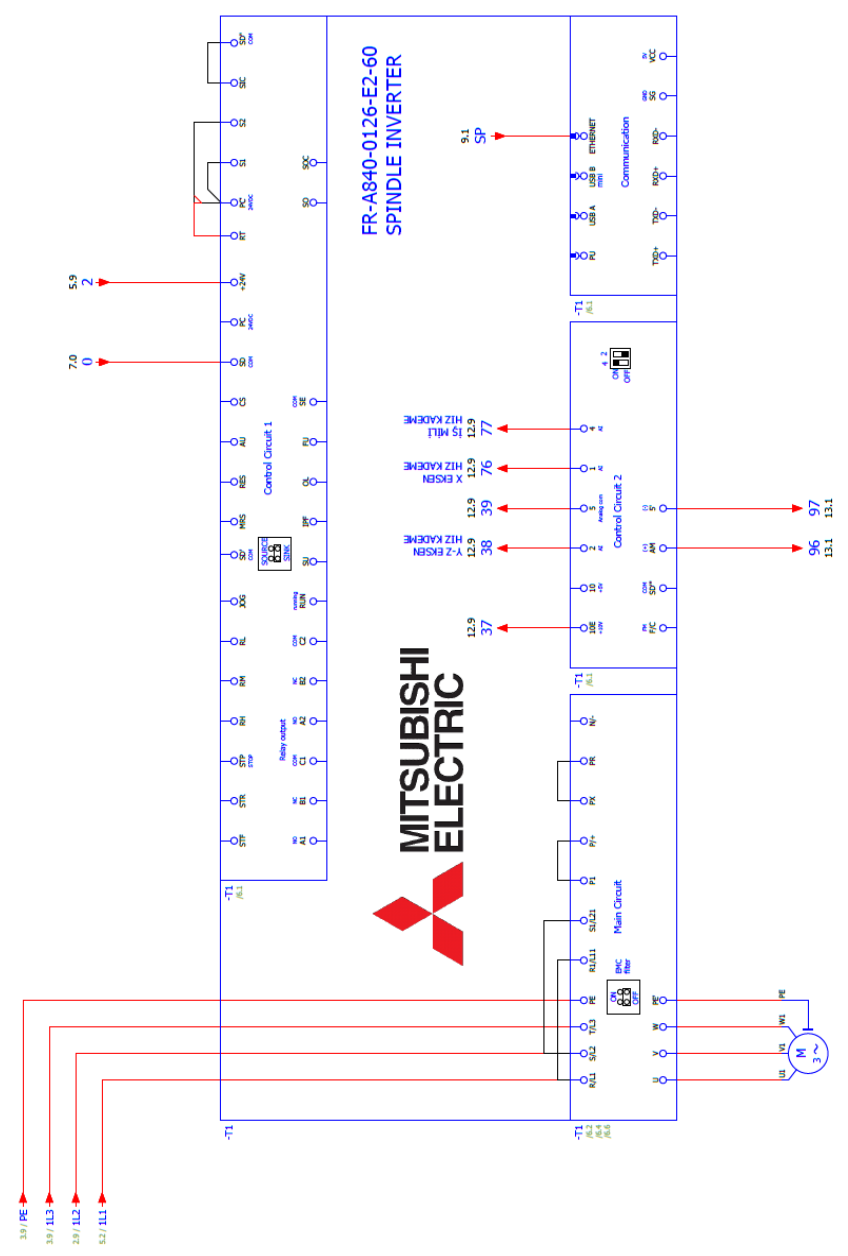

Şekil 4. İş Mili Sürücü Projesi

\subsection{PLC Yazılımı}

$\mathrm{Bu}$ çalışmada; makine, eksen motorları, sürücüler, iş mili motoru eviricisi, ekran ve PLC bir set olarak kullanıldığından bu PLC'ye ait arayüz tasarım programı olan GT Designer3 Versiyon 1.217B programı kullanılmıştır. PLC'de programlama kodlama, ladder diyagramı ya da fonksiyon blokları kullanılarak yapılabilirken, bu çalışma sırasında daha çok ladder diyagramı ile programlama tercih edilmiştir.

Arayüz, eksen hareketlerinin, ekrandan girilen değerlerin PLC ile yorumlanıp, makinenin çalışmasını ve komutlandırılmasının daha basit şekilde yapılmasını sağlar. $\mathrm{Bu}$ çalışma sırasında; gitme komutu, miktar bilgisi, iş mili devir bilgisi, mod bilgileri, hız bilgisi ve pozisyon bilgisi PLC için girdi bilgileri olarak seçilmiş, alarm, tarih/saat bilgisi, zorlanma bilgisi, işlem sonu bilgisi, referans bilgisi ve güvenlik önlemleri çıkış bilgisi olarak tercih edilmiştir. Ayrıca yüzey taşlama ve alın taşlama için de iki farklı seçenek belirlenmiştir. Yüzey taşlamada parçanın kesme yönü $Z$ ekseninde, ilerleme yönü ise $Y$ ve $X$ eksenlerindedir. Alın taşlamada zımpara taşının yan yüzeyleri kesme yapar. Kesme yönü $\mathrm{Y}$ ekseni, ilerleme yönü ise $\mathrm{X}$ ve $\mathrm{Z}$ eksenleridir. Bunun yanı sıra hem otomatik hemde manuel (elle) çalışma seçenekleri eklenmiştir. Şekil 5 ile taşlama makinasının kontrolü sırasında kullanılan elemanlara ait bir yap1 gösterilmektedir. 


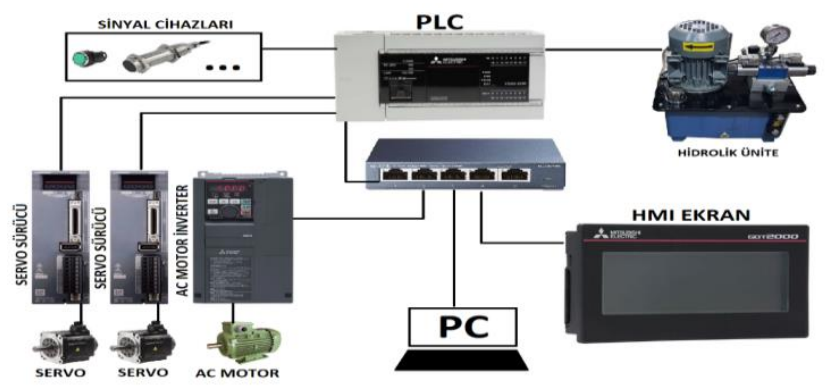

Şekil 5. Taşlama makinasına çalışmasına ait bir görünüm

Ana sayfa ve diğer sayfalar (ayar sayfası vb.) HMI ekran ile Ethernet kablosu üzerinden PLC ye bağlanmakta ve haberleşerek üzerindeki verileri PLC'ye göndermektedir. PLC bu verileri alarak değerlendirir ve motorlara veya diğer çıkış elemanlarına komut gönderir. Örneğin; motorda gönderdiği gitme komutundan sonra motor hangi konumda olduğunu PLC ye bildirir ve bu bilgiyi PLC ekrana yansıtır. Makine istenen yere gidememişse, bir zorlanma olmuş, motor durmuşsa alarm bilgileri ekrana yansıyacaktır. Yapılan ayarlarla kullanıcıya ilk olarak yüzey taşlama mı veya alın taşlama mı yapılacağı sorulur. Daha sonra; yüzey taşlama seçilmiş ise parçanın Y ön pozisyonu, $\mathrm{Y}$ arka pozisyonu, $\mathrm{Z}$ yüzey pozisyonu ve taşlamada alacağı paso, toplam paso, Y kayma miktarı değerleri girilebilir. Şekil 6 ile yüzey taşlama seçildiği takdirde karşılaşılacak ekran görüntüsü verilmektedir.

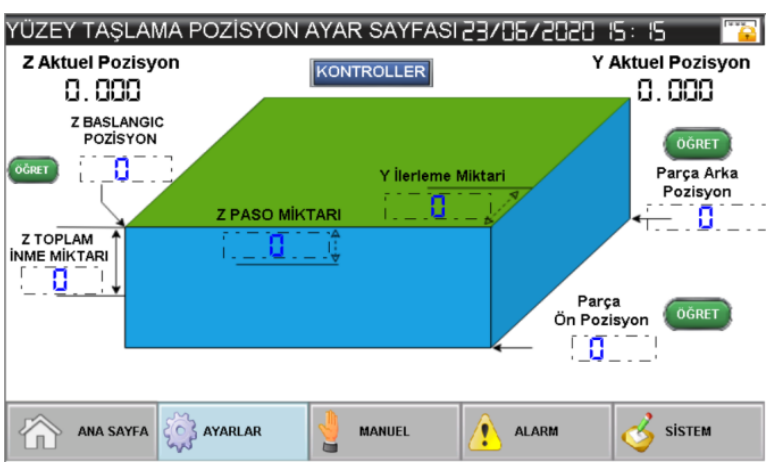

Şekil 6. Yüzey Taşlama Sayfası

Sistemin haberleşmesi ethernet çoklayıcı ile sağlanmıştır. Sistem içerisinde dokunmatik ekran, AC motor eviricisi, PLC sistemin yazılımlarının yazılabileceği PC bağlantıları için 4'lü Ethernet çoklayıc1 monte edilmiştir. Şekil 7'de sisteminçalışmasına ait bir akış blok diyagramı gösterilmektedir.

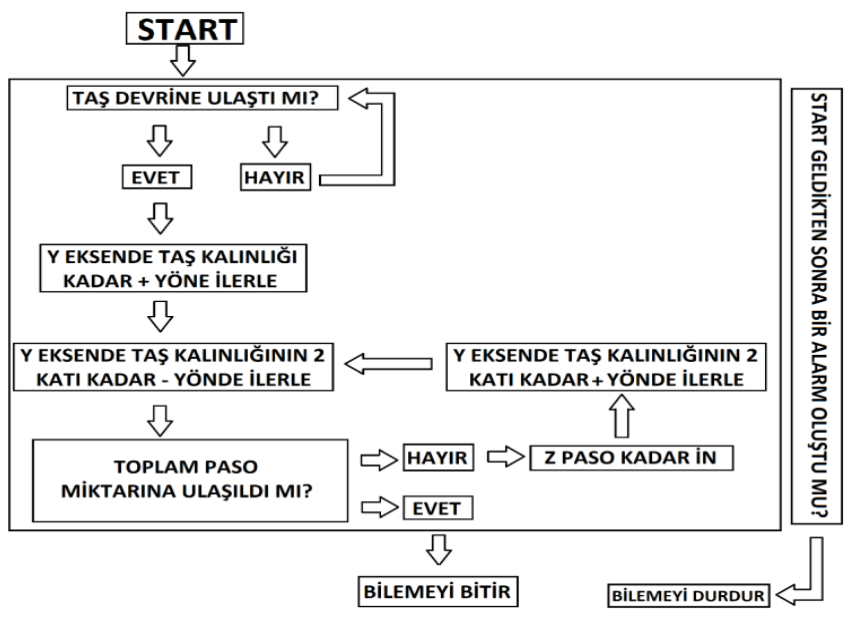

Şekil 7 Sistemin Çalışmasına Ait Blok Diyagramı
PLC programı kullanılarak gerçekleştirilen bileme işlemine ait programa ait bir görsel Şekil 8 ile gösterilmektedir.

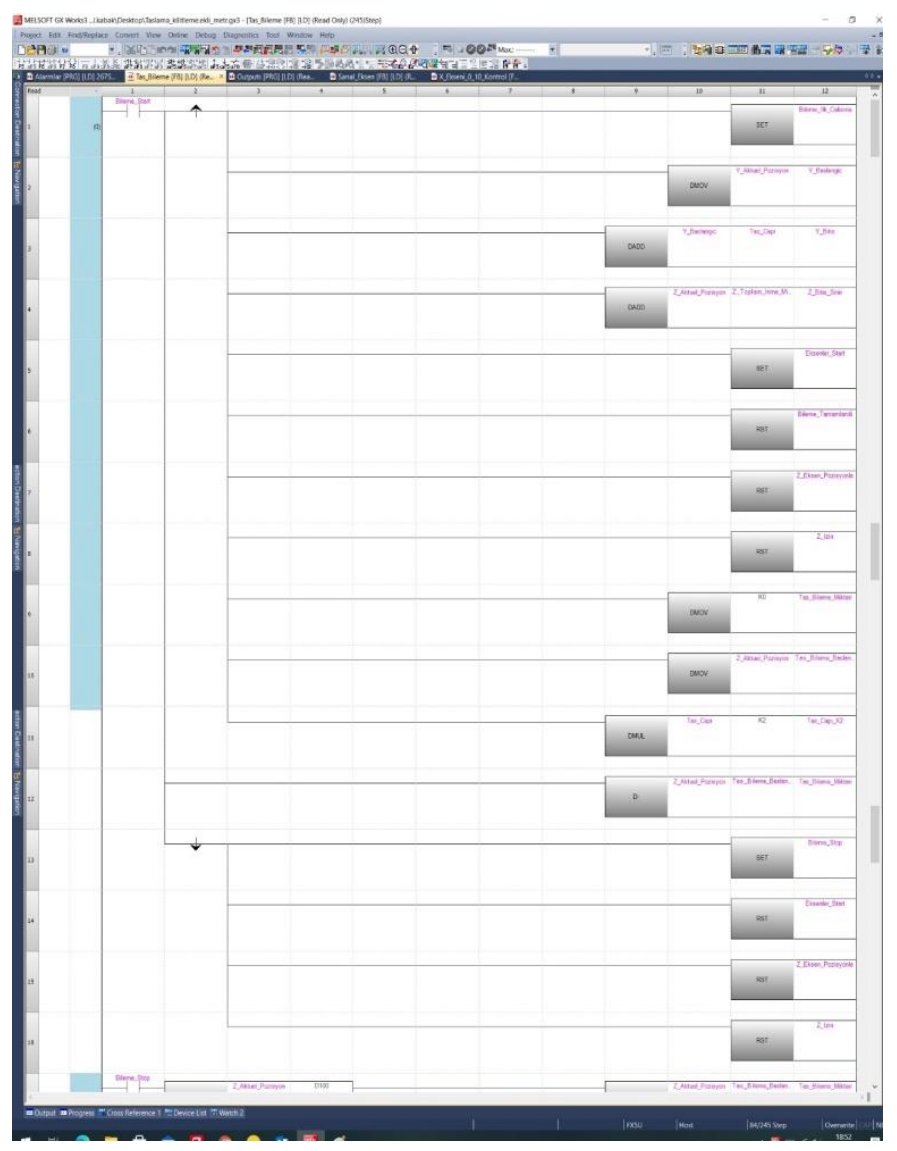

Şekil 8. Bileme İşlemine ait Ladder Diyagramı.

Taş bileme tamamlandıktan sonra bilenen miktar kadar taş küçüleceği için bu değer parça sıfırının yerini değiştirecektir. Bu nedenle bileme tamamlandıktan sonra bilenen kadar değer parça yüzey seviyesine eklenir. Bu sayede küçülen taş parça sıfırını etkilememiș olacaktır. Operatörün bilenen kadar değeri değiştirmesi gerekmeyecek bunu yazılım otomatik olarak yapmış olacaktır. Bu durum Şekil 9'de verilen Ladder diyagram ile gösterilmektedir.

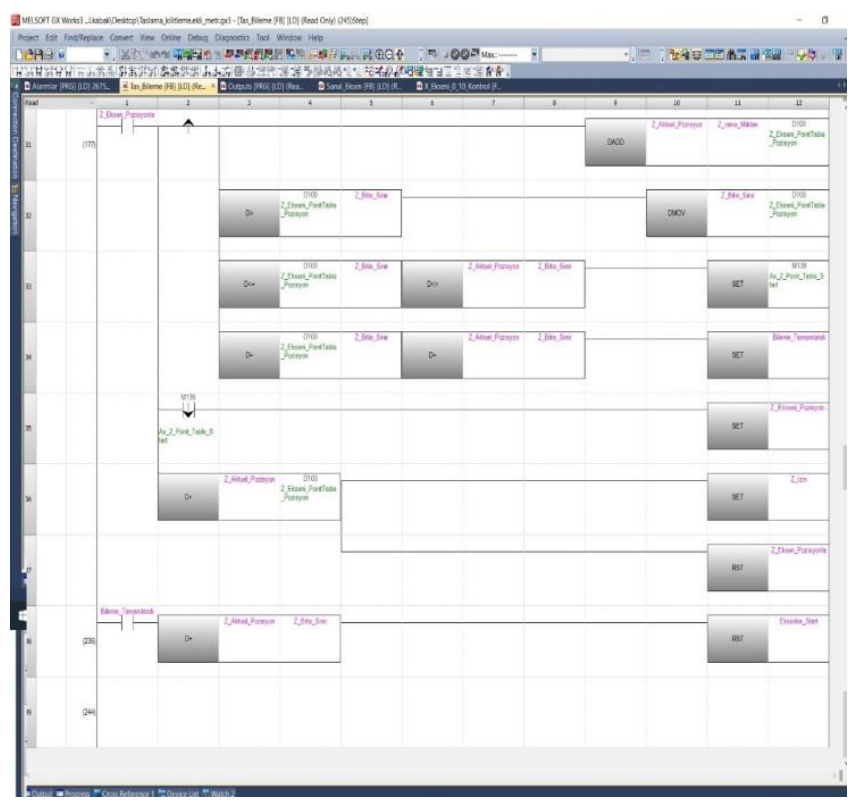

Şekil 9. Taş Bileme Bitişe ait Ladder Diyagramı 


\section{Sonuç}

Makinelerin daha hassas ve verimli şekilde çalıştırılması sağlanarak endüstriye kazandırılması için otomasyon kısmının hatasız olarak yazilması ve sisteme entegre edilmesi gerekir. Bunun dışında yapılan çalışmanın, hataları en aza indirmek, işin yapılış zamanını azaltmak, kişilere bağlı olmamak veya daha hassas işleme yapmak konularından en az birine de cevap vermelidir. Bu çalışmada taşlama makinelerinin PLC ve HMI kontrolü ile yapılan çalışmalarında verimi artırmak amacıyla zaman zaman her parça için $30 \mathrm{dk}$ zaman kaybına sebep olan bileme işlemini otomatik olarak yapılması ele alınmıştır. $\mathrm{Bu}$ işlemin otomatik olarak yapılması ile endüstride önemli olan 30 $\mathrm{dk}$ gibi bir sürenin yaklaşı $10 \mathrm{dk}$ ya indirilmesiyle $\% 33$ e kadar zaman tasarrufu sağlamanmıştır. Aynı zamanda makine, parçada ölçü bozulmasını engelleyerek verimin artırılması sağlanmıştır. Bunun yanı sıra işlenecek parça cinsine ve formuna göre taş bileme yapılarak aşındırıcının daha uzun süre dayanması ile tasarruf sağlanması amaçlanmıştır.

\section{Teșekkür}

Yazalar bu çalışma sırasında katkılarından dolayı Taksan Makina Sanayi ve Ticaret Anonim Şirketi'ne teşekkür eder.

\section{Kaynakça}

[1]. Laughton M. A.,Warne D. J. (2003). Electrical Engineer's Reference book, Newnes, Chapter 16 Programmable Controller.

[2]. Soylu, (2013). Endüstri 4.0 ve Girişimcilikte Yeni Yaklaşımlar, Pamukkale Üniversitesi Sosyal bilimler Enstirüsü Dergisi, Sayı 32, sayfa 43-57.

[3]. Gelen, S., Onur, B. (2020) Endüstri 4.0 uyumlu DC Wattmetre Tasarımı, Dicle Üniversitesi Mühendislik Mimarlık Fakültesi Dergisi, Sayı 11 (3), sayfa 907-913.

[4]. Gorecky, D., Schmitt, M., Loskyll M. ve Zühlke, D. (2014) Human-machine-interaction in the Industry 4.0 Era, 12.
IEEE International Conference on Industrial Informatics, Brasil, sayfa 89-294.

[5]. Uğuz, S., Zehir, B (2020). İmalat Mühendisliği Eğitimi için Sanal Gerçeklik Sistemi ve Tasarımı ve Geliştilmesi, GU J Sci, Part C, 8(4), 845-857.

[6]. Dengiz, Orhan (2017). Endüstri 4.0 Üretimde Kavram ve Alg1 Devrimi, Makine Tasarım ve İmalat Dergisi, 15(1), $38-45$.

[7]. Gandhi A., Sangeetha M. (2018). Development of an Image Processing Algorithm for Smart CNC Machines. IEEE Transactions on Smart Processing \& Computing, 7 (3) $232-235$.

[8]. Londono J.C., Mario L.E., Mora R. (2018). Positioning of the Cutting Tool of a CNC Type Milling Machine by Means of Digital Image Processing, In Advances in Computing CCC 2018.

[9]. Lopera J.C.L., Mora J.E.G., Mesa E. (2018). "Positioning of the Cutting Tool of a CNC Type Milling Machine by Means of Digital Image Processing”. In Colombian Conference on Computing.

[10]. Öztürk, S., Kuncan, M. (2020). "Kameradan Alınan Görüntünün CNC Tezgâhında Gerçek Zamanlı Olarak İşlenmesi”. BEÜ Fen Bilimleri Dergisi, 9(3), 1251-1263.

[11]. Mirzaoğlu, İlteriş (2008). PLC ve SCADA Kullanarak İrmik Üretim Sisteminin Otomasyonu.. Ankara ,Gazi Üniversitesi Fen Bilimleri Enstitüsü, Yüksek Lisans Tezi.

[12]. Özen, F., Şimşek, M.A. (2019). "Realization of A Building Automation System Using PLC And SCADA". International Journal of Engineering and InnovativeResearch, 1(1), s. 28-34.

[13]. Özen, F., (2019). "PLC ve SCADA Kullanarak Bir Bina Otomasyon Sisteminin Gerçeklenmesi, Uzaktan Kontrolü ve İzlenmesi". Tekirdağ Namık Kemal Üniversitesi Fen Bilimleri Enstitüsü, Yüksek Lisans Tezi. 